\title{
Association of Clinical Pathologists: 72nd general meeting
}

The 72nd general meeting of the Association of Clinical Pathologists was held at the Medical School, Bristol University, on 9, 10, and 11 April 1964. At this meeting three symposia were held, one on forensic pathology, one on non-tuberculous urinary infection, and the third on functional aspects of liver disorder. There were also three groups of unrelated papers. Abstracts of some of the papers read at the symposia and at the general meeting follow.

\section{THE CLINICAL USE OF SERUM PEPSINOGEN}

N. K. SHINTON and A. K. SINGH (Cardiff) had estimated the level of serum pepsinogen in 62 normal adult subjects, in 18 patients with duodenal ulceration, and in 76 patients with various types of anaemia. The range in the normal group had been found to vary from 55 to 482 units $/ \mathrm{ml}$. (mean 187 units/ml.), there being little difference with age or sex. The patients with duodenal ulcers had a range of 215 to 670 units $/ \mathrm{ml}$. (mean 347 units $/ \mathrm{ml}$.), whereas 45 patients with pernicious anaemia had levels of 5 to 119 units $/ \mathrm{ml}$. (mean 36 units $/ \mathrm{ml}$.), with no difference between the treated and untreated groups. The range and mean values for the other groups of patients with anaemia, including 11 cases of nutritional megaloblastic anaemia, were similar to those for normal subjects. In view of the wide overlap in values found in normal persons and patients it was concluded that only levels below 80 units $/ \mathrm{ml}$. were of diagnostic importance and that these may be indicative of gastric atrophy. The estimation was therefore considered to be of only negative value in the diagnosis of duodenal ulceration but of clinical use in the differential diagnosis of megaloblastic anaemia where a low level was suggestive of pernicious anaemia.

A GALACTOSAEMIC INFANT WITH A POSSIBLE NEW INBORN ERROR OF METABOLISM

B. R. BEVAN and J. B. HOLton (Bristol) Two siblings, who presented with jaundice and vomiting at the age of a few days, showed very similar biochemical abnormalities. Both had galactosaemia and a picture of hepatic obstruction. Both died before 6 weeks of age. On one baby it was possible to perform further investigations.

In this baby the red cell galactose-1-phosphate uridyl transferase was normal, as was the Schwarz test for measuring the metabolism of galactose-1-phosphate by the red cells. Raised pyruvate levels were found in blood and urine. At the same time, blood lactate was below normal and there was very little oxoglutarate in the urine.

On the basis of these results, it was concluded that there was a block in the metabolism of pyruvate and resultant lack of tricarboxylic acid cycle activity. In these conditions the production of $\mathrm{NADH}_{2}$ would be decreased and conversion of pyruvate to lactate would be reduced, as was indicated by the finding of a low blood lactate level in the patient.

\section{CHRONIC PHENACETIN NEPHROPATHY}

N. G. SANERKIN (Cardiff) Two cases of 'chronic phenacetin nephropathy' (chronic interstitial nephritis with papillary necrosis) were presented, both in women who had consumed excessive amounts of mixtures containing aspirin, phenacetin, and codeine for a long time. Neither had diabetes mellitus or obstructive uropathy.

Case 1 suffered from migraine for over $\mathbf{4 0}$ years (total consumption of phenacetin about $8 \mathrm{~kg}$.) and died in uraemia. The kidneys showed severe uneven unequal contraction, with occasional islands of uncontracted tissue. Most of the papillae were necrotic, with severe atrophy and fibrosis of the related renal parenchyma. Uncontracted areas showed tubular dilatation and slight interstitial oedema.

Case 2 suffered from severe thalamic pain $(10-17 \mathrm{~kg}$. phenacetin over 15 years) and died from aspiration pneumonia. A few papillae were macroscopically necrotic, with moderate atrophy and fibrosis of the renal parenchyma; other papillae showed superficial erosions and microscopic necrosis.

Phenacetin is the only drug common to the numerous analgesic mixtures which have been implicated in this syndrome. The condition was first described by Spuhler and Zollinger (1953) who considered it to be an abacterial 'primary chronic interstitial nephritis'. Bengtsson (1962), among others, believes that it is a variant of nonobstructive chronic pyelonephritis; he suggests that phenacetin is often the primary factor in the renal damage, although not necessarily the only factor. The pathogenesis of the condition is still in dispute. It is therefore best described in non-committal terms as chronic papillary necrosis with renal parenchymal atrophy and fibrosis.

\section{REFERENCES}

Bengtsson, U. (1962). Acta med. scand., Suppl., 388. 


\section{PLATELET STICKINESS: SOME METHODS AND SOME THEORY}

J. R. O'BRIEN (Portsmouth and Isle of Wight Area Pathological Service) At least two functions of platelets are involved in thrombus formation, platelet adhesion to a surface and platelet adhesion to each other-aggregation. The simplest surface to study is glass, and the methods of Payling Wright, Moolten and Vroman, Hellem and O'Brien were considered. These simple methods have advantages and grave theoretical disadvantages. The more physiological experimental methods of Mustard's arteriovenous shunt and the 'white body' formation of Honour and Ross Russell were mentioned. The best method to date for studying platelet aggregation is probably that which measures and records continuously the optical density of stirred platelet-rich plasma, since more light passes through aggregated platelets than through dispersed single platelets.

Some observations distinguish sharply between adhesion and aggregation although there are evidently similarities in these two situations. However, the basic mechanism and the forces involved in platelet 'stickiness' are unknown. Platelet aggregation induced by A.D.P., 5-H.T., adrenaline and noradrenaline occurs immediately and platelets normally contain A.D.P., 5-H.T., and probably catecholamines. On the other hand thrombin, tri-ethyl tin, and collagen cause aggregation only after a delay which suggests that different mechanisms may be involved. Aggregation induced by all these agents is inhibited by adenosine and A.M.P. and these two compounds inhibit the effect of added A.D.P. Thus perhaps intrinsically formed A.D.P. or possibly the action of an A.T.P.-ase is the common factor resulting in stickiness. The dramatic effect of the specific inhibitors on 5-H.T. and adrenaline-induced aggregation suggests that platelets have specific receptor sites for these compounds.

\section{THE APPLICATION OF MODERN SEROLOGICAL TECHNIQUES} TO FORENSIC MEDICINE

MARGARET PEREIRA (London) Until comparatively recently, examination of bloodstains was limited to determination of species origin by precipitin methods and to determination of the ABO groups by the inhibition technique. Fairly large stains were necessary for these tests.

New techniques have been evolved which are considerably more sensitive. These include the mixed agglutination technique (Coombs, Bedford, and Rouillard, 1956) and absorption-elution methods (Kind, 1960a and b; Nickolls and Pereira, 1962; Outteridge, 1962). By mixed agglutination and micro-absorption-elution (Nickolls and Pereira, 1962) reliable results can be obtained from very small bloodstains and stains of semen and saliva can also be grouped. Mixed agglutination can be used for grouping skin and dandruff (Swinburne, 1962), and absorptionelution for grouping finger nails (Outteridge, 1963) and for the determination of $\mathrm{MN}$ groups of bloodstains (Pereira, 1963). Gm factors can also be identified (Neilsen and Henningeen, 1963; Planques, Ruffle, and Ducos, 1961).
It is possible that fluorescent antibody techniques maye be developed for grouping dried bloodstains.

New approaches for determination of species origin: include a mixed agglutination technique (Coombs an $\Phi_{\text {? }}$ Dodd, 1961 and the use of fluorescent antibody (Culliford unpublished data).

Recent trends with precipitin reactions have beer towards gel diffusion methods. A highly specific anti: human seminal serum has been developed with geb diffusion (Coombs, Richards, and Dodd, 1963). A gep electrophoresis method has also been described (Culliford, 1964). This is rapid, highly sensitive and particularly useful in species identification of fatty tissues.

Methods have also been described for the determin ation of haptoglobin and haemoglobin groups in blood $\overline{-}$ stains (Culliford, 1963).

\section{REFERENCES}

Coombs, R. R. A., Bedford, D., and Rouillard, L. M. (1956). Lanceto 1, p. 461. , and Dodd, B. (1961). Med. Sci. \& L. 1, 359.

-, Richards, C. B., and Dodd, B. (1963). Ibid., 3, 65.

Culliford, B. J. (1963). Nature, 198, 4882, 796.

(1964). Ibid., 201, 1092.

(to be published in $J$. For. Sci. Soc.).

Kind, S. S. (1960a). Nature, 185, 397.

(1960b). Ibid., 187, 789.

Neilsen, J. C., and Henningeen, K. (1963). Med. Sci. \& L., 3, 49.

Nickolls, L. C., and Pereira, M. (1962). Ibid., 2, 172.

Outteridge, R. A. (1962). Nature, 4826, 385.

(1963). Med. Scl. \& L. 4, 275.

Pereira, M. (1963). Med. Sci. \& L., 4, 268.

Planques, J., Ruffle, J., and Ducos, J. (1961). Toulouse-Medical, 9, 6850 Swinburne, L. M. (1962). Ibid., 3, 3.

BACTERIOLOGICAL COMPLICATIONS FROM THE USE OF URETHRAL INSTRUMENTS

J. P. MITCHELl (Bristol) The investigations into the causes of urinary tract infection were described with particular reference to the operation of prostatectomy and the long-term preliminary drainage of obstructee bladders which had resulted in hydronephrosis. Bacter? aemia, following instrumentation of the urethra for dilatation of a urethral stricture or when the posto operative catheter is removed, was discussed and the risks of infection of the urinary tract in women from post-operative indwelling catheters was shown to be considerable.

Problems involved in sterilizing cystoscopes and other endoscopic instruments were shown to present peculiar features because most of the standard method of sterilization either damaged the instrument or, as ino the case of formalin, carried some risk to the patient from the removal of formalin particles onto the urethrat mucosa. Pasteurization was probably the best method of sterilizing cystoscopes, but this could mean a delay of as long as $\mathbf{2 0}$ minutes if a certain endoscopic instrument was required unexpectedly.

As a result of guidance from bacteriologist colleagues and the implementing of certain theatre and war $\$$ disciplines, results of urological surgery have beeno vastly improved, and, in particular, there has been a 
dramatic success in the treatment of chronic retention, with advanced renal failure, and almost complete disappearance of bacteriaemias following the withdrawal of catheters or the passage of urethral dilators.

\section{PATHOGENESIS OF PYELONEPHRITIS}

W. BRUMFITT (Edgware General Hospital and St. Mary's Hospital, Paddington) Urinary tract infection is defined as the condition in which the bacterial count exceeds $10^{5}$ per ml. bladder urine. Such urinary tract infection may be accompanied by cystitis, pyelitis, or pyelonephritis.

The most usual route of infection is the ascending one in which urethritis is progressively followed by cystitis, pyelitis, and pyelonephritis but many infections are confined to the bladder because of the presence of a valve at the lower end of the ureter. Under normal circumstances the vesico-ureteric valves isolate the bladder from the upper urinary tract but inflammation and oedema of the bladder wall may cause temporary incompetence of one or both of these valves with the result that infected urine reaches the renal pelvis and initiates infection.

The vast majority of primary infections are due to Esch. coli and many cause no symptoms. The lack of symptoms, however, is no guarantee against involvement of the upper urinary tract.

Certain specific Esch. coli O-types are common in urinary tract infection and these are not found with equal frequency in the faeces. This suggests that these organisms have a special pathogenicity for the urinary tract.

The evidence at present available indicates that chronic pyelonephritis is the result of persistent or recurrent infection of the urinary tract. Because both human pyelonephritis and experimental pyelonephritis in animals can be found in the absence of arterial disease, it is unlikely that ischaemia plays a primary role in the aetiology of the condition. The extensive fibrosis and round cell infiltration seen histologically and the similarity to transplanted kidneys has led to the suggestion that chronic pyelonephritis is due to an auto-immune process initiated at the time of the acute pyelonephritic episode. However, many patients give no history of a classical attack of acute pyelonephritis and a search for kidney antibodies in patients and experimental animals has so far been unrewarding.

\section{LABORATORY DIAGNOSIS OF URINARY INFECTIONS}

A. PERCIVAl (Edgware General Hospital) The finding of 100,000 or more bacteria per millilitre of urine indicates the presence of actively multiplying bacteria in the bladder urine and quantitative bacterial counting carried out on the urine will differentiate between contamination and true bacterial infection. Examination of urine specimens from large numbers of individuals in different population groups has demonstrated a surprisingly high incidence of individuals with significant bacteriuria in the absence of any symptoms referrable to the urinary tract. This suggests a necessity for the general introduction of routine screening of the urine which would place a heavy load upon bacteriological laboratories.

To define the most reliable and economical screening test, studies were carried out at Edgware General Hospital using different tests in parallel with quantitative counting in urines from 1,136 hospital patients and 3,000 women attending the ante-natal clinic. Methods used were the nitrite and tri-phenyl tetrazolium chloride chemical screening tests, direct plating of a loopful of uncentrifuged urine, and a filter paper strip technique. The filter paper strip technique gave the most accurate correlation with quantitative counting and was by far the most economical in both time and materials.

Methods for detecting the presence of excess white cells in the urine were discussed and the practice of culturing only urine with excess white cells was criticized on the grounds that although an excess was found in $95 \%$ of 326 patients with symptomatic urinary infection, in $43 \%$ of 163 women with bacteriuria of pregnancy the urinary white cell count was normal.

\section{SOME DISORDERS OF BILIRUBIN METABOLISM}

J. B. HOLTON (Southmead Hospital, Bristol) The hepatic metabolism of bilirubin may be considered in three stages. 1 The transport of bilirubin from blood, where it is bound to albumin, to within the liver cell. This mechanism may be defective in Gilbert's disease. 2 The conjugation of bilirubin with glucuronic acid, in the microsomes, The enzyme for this reaction is absent in the CrigglerNajjar syndrome and is not fully active in the newborn infant. 3 The transfer of bilirubin diglucuronide from microsomes to the bile ducts. There is some defect in this process in the Dubin-Johnson syndrome and in intrahepatic cholestasis.

Bilirubin metabolism can be studied in liver preparations and may be inhibited in various ways. Lathe and Walker (1958) found that newborn infant's serum inhibited bilirubin conjugation by rat liver slices, and four active compounds were isolated from the serum (Holton and Lathe, 1963). Two of these compounds were identified as $5 \beta$-pregnane- $3 \alpha, 20 \alpha$-diol and $3 \alpha$ hydroxy$5 \beta$ pregnane-20-one. It was shown that one of these compounds inhibited conjugation by liver slices.

Recent work had indicated that some compounds which affect bilirubin metabolism in vitro cause jaundice. Novobiocin, which produces unconjugated hyperbilirubinaemia in the newborn, inhibited bilirubin conjugation by rat liver homogenates (Hargreaves and Holton, 1962). This compound may also affect bilirubin diglucuronide excretion (Hargreaves and Lathe, 1963). Arias and Gartner (1963) found that mothers of some infants with persistent jaundice had an inhibitor of bilirubin conjugation in their breast milk. This was identified as pregnane-3 $\alpha, 20 \beta$ diol.

\section{REFERENCES}

Arias, and Gartner, (1963). Presented to the American Society for Clinical Investigation, Atlantic City, New Jersey.

Hargreaves, T., and Holton, J. B. (1962). Lancet, 1, 839.

-, and Lathe, G. H. (1963). Nature (Lond.), 200, 1172.

Holton, J. B., and Lathe, G. H. (1963).

Lathe, G. H., and Walker, M. (1958). Quart J. exper. Physiol., 43, 257. 


\section{5-HYDROXYTRYPTAMINE IN PORTAL HYPERTENSION}

CHRISTINE TYLER, J. H. PEACOCK, and CHRISTINE SMITH (Bristol) The concentrations of 5-hydroxytryptamine were measured in the portal and peripheral venous blood of patients with intrahepatic type of portal hypertension and normal controls. The effect of an end-to-side portacaval anastomosis on the peripheral venous levels was also assessed. The peripheral levels of patients in hepatic coma were compared with those of fully conscious patients with cirrhosis, and the levels of 5-H.T. in cerebrospinal fluid in the former with a series of noncirrhotic controls.

The method of estimation was that of Crawford and Rudd (1962) using an Aminco-Bowman spectrophotofluorimeter. Each determination was carried out on $2 \mathrm{ml}$. of platelet-rich plasma.

The results show that the peripheral venous concentrations of 5-H.T. in the cases of cirrhotic portal hypertension are significantly lower than those in normal controls. This is in contrast to the findings of Magdelaine et al. (1962) who, using a less sensitive method, reported values higher than normal in such cases. At operation the concentrations in the portal vein are usually higher than those found in peripheral venous blood. End-toside portacaval anastomosis has no significant effect on the peripheral venous levels in the majority of cases, but in those with poor liver function a rise in concentration may occur post-operatively. The peripheral levels of 5-H.T. in patients in hepatic coma are comparable to those found in the conscious group of portal hypertensives. In contradistinction to the high values reported by Southern (1962), the cerebrospinal fluid levels in hepatic coma appear to be within normal limits.

It is concluded that 5-H.T. is not specifically linked with the development of the hypertensive state in patients with intrahepatic portal hypertension.

\section{REFERENCES}

Crawford, N., and Rudd, B. T. (1962). A spectrophotofluorimetric method for the determination of serotonin (5-hydroxy-tryptamine) in plasma. Clin. chim. Acta, 7, 114.

Magdelaine, M., Dreux, C., Bonvarlet, A., and Leger, L. (1962). Serotonin in portal hyperrension. Its changes in the blood before and after surgical portal shunting. Presse méd., 70, 7.

Southern, A. L., and Christoff, N. (1962). Cerebrospinal fluid serotonin in brain tumour and other neurological disorders determined by a spectrophotofluorometric technique. J. Lab. clin. Med., 59, 320.

\section{HISTOCHEMICAL EVIDENCE OF LIVER DISEASE}

LUCILLE BITENSKY (The Royal College of Surgeons, London) Alkaline phosphatase and transaminase levels in the serum are of value in assessing established liver disease. The value of histochemistry applied to fresh needle biopsies is that while it can mirror the serum estimations in relatively gross disease, it can disclose not only earlier stages of cellular disorder but also localize its site.

Clinically the obvious potential advantage of the histochemistry of alkaline phosphatase would be to distinguish between obstructive and hepatitis jaundice $\stackrel{0}{=}$ (Sherlock and Walshe, 1947). Unfortunately, inadequacies 으 in histochemical technique have brought this procedure into disrepute. Recent improvements, by the present $\stackrel{\vec{S}}{\stackrel{F}{ }}$ author, have resulted in precise localization of this $\overline{0}$ enzyme so that, not only does the histochemical assess- $\frac{\bar{\sigma}}{\sigma}$ ment correspond to the levels found in the serum, but it $\overline{\bar{c}}$ allows the diagnosis of cellular disorder to be made even $\overrightarrow{\mathbb{D}}$ where the biochemical results are equivocal. It is likely $\varrho$ that this improved procedure will be significant in the differentiation between obstructive and hepatocellular $\overrightarrow{0}$ jaundice.

Transaminases cannot be distinguished histochemically, $\overrightarrow{\vec{\omega}}$ but recent investigations suggest that the levels of the $\mathcal{\sigma}$ linked glutamic dehydrogenase may be even more significant in assessing cellular damage. Histochemical studies on this enzyme, both in experimentally induced $\vec{V}$ cellular disorders and in clinical material, have indicated that this enzyme is a delicate marker for this system and may indicate disorder long before necrosis occurs.

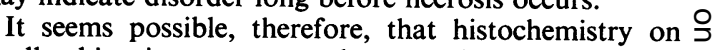
needle biopsies may greatly extend the diagnostic potentialities of the clinical pathologist.

\section{REFERENCE}

Sherlock, S., and Walshe, V. (1947). J. Path. Bact., 59, 615.

SOURCES OF ERROR IN ANTIBIOTIC SENSITIVITY TESTING

A. H. LINTON (Department of Bacteriology, University of Bristol) In the antibiotic agar diffusion technique inhibition zones are the end-result of two dynamic systems interacting simultaneously. The zone is formed when a definite population of cells is reached by multiplication of the inoculum. The time required for this varies according to the inoculum size used and the rate of growth of the test organism. Diffusion of the antibiotic is proceeding during this time and the distance reached by an inhibitory concentration is proportional to the length of time determined by the growth of the inoculum.

Three possible sources of error in this test were considered.

Inoculum size The profound effect of inoculum size was illustrated and criticism made of the primary inoculation technique in which inocula size is not controlled. Valid tests must be done on pure cultures using standardized inocula.

Medium constitution The constitution of the test media may have a profound effect on zone size. Small zones were obtained with streptomycin on a sensitivity agar due to antagonists in the medium. This could result in reporting lower sensitivity on a test strain unless comparison with a known sensitive strain is made.

Diffusion coefficient Zones of similar size were $\stackrel{\mathscr{P}}{?}$ obtained with discs containing $25 \mu \mathrm{g}$. streptomycin and $25 \mu \mathrm{g}$. chloramphenicol. Quantitative determinations revealed the test organism to be four times more resistant to chloramphenicol but this difference was compensated, in the sensitivity test, by the faster rate of diffusion of chloramphenicol. Zones of equal size with different antibiotics do not necessarily indicate equal sensitivity. 
TETRACYCLINE LEVELS IN BRONCHIAL SECRETIONS

M. J. CAMPBELL (Wright-Fleming Institute of Microbiology, St. Mary's Hospital, Paddington) Tetracyclines are widely used in bronchitis but often give relief rather than elimination of bacterial pathogens. This is probably related to the difficulty of access of tetracycline to the bacterial pathogens. This report is of the tetracycline levels in bronchial secretions of patients on oral tetracycline therapy.

Twenty-four hour sputum collections were made in 40 patients receiving tetracycline $\mathrm{HCl}, 250 \mathrm{mg}$. four times daily. The sputa were rendered into homogeneous solutions by two separate methods. The first was by proteolytic digestion with p-Pronase (Nomoto and Narahashi, 1959) and the second by ultracentrifugation at $103,000 \mathrm{~g}$ for three hours (Gibbons, 1959 and 1962) which produced a non-viscous supernatant comprising $80-90 \% \mathrm{w} / \mathrm{w}$ of the original sputum.

Assays were performed by a large plate agar diffusion method incorporating $B$. Cereus spores as the test organism (modified after Grove and Randall, 1956).

The sputum tetracycline levels were found to be very variable but were generally $10-30 \%$ of the average serum level in each patient. The supernatant and Pronasedigest levels correlated fairly closely, but the latter were usually slightly higher. Analysis of assays in all patients showed that with a serum level of $2 \cdot 0$ to $4.0 \mathrm{mg} . / \mathrm{ml}$. tertacycline, the sputum level was 0.38 to $1.5 \mathrm{mg} . / \mathrm{ml}$. for whole sputum and 0.29 to $1.5 \mathrm{mg}$. $/ \mathrm{ml}$. for the supernatant.

The sputum levels are related to the estimated minimum inhibitory concentration of tetracycline for 29 strains of $H$. influenzae. Eighty-six per cent of these strains were sensitive to $0.5 \mathrm{mg} . / \mathrm{ml}$. tetracycline, which is within the sputum range of most patients on $1 \mathrm{~g}$. tetracycline daily.

\section{REFERENCES}

Gibbons, R. A. (1959). Biochem. J., 73, 209.

- (1962). Nature (London), 196, 290.

Grove, and Randall (1956), Assay Methods of Antibiotics. Academic Press, New York.

Nomoto, and Narahashi (1959). J. Biochem. (Tokyo), 46.

\section{THE HUMAN HAIR AS A RESERVOIR OF STAPHYLOCOCCI}

MARGARET M. SUMMERS, P. F. LYNCH, and T. BLACK (Liverpool) The chance finding of Staphylococcus aureus in the hair of nurses prompted the investigation of the carriage of staphylococci in the hair of the human head. Three groups were studied: (1) 100 out-patients on first attendance; (2) 422 in-patients before operation, and (3) 164 doctors and nurses.

Heads were sampled by pressing $5 \%$ horse blood agar plates against the scalp so that the hair inoculated the surface of the agar and nasal swabs were taken at the same time.

Thirty-seven per cent of out-patients, $40 \%$ of in-patients, and $27 \%$ of hospital staff carried Staphylococcus aureus in their hair. More hair carriers than nasal carriers were found and on average $20 \%$ of hair carriers were found not to have Staphylococcus aureus in the nose.
In hospital staff and in-patients the staphylococci were highly resistant to antibiotics and were of phage types usually classified as 'hospital staphylococci'.

There was a greater incidence of staphylococcal post-operative wound infections in hair carriers than in non-carriers and in three cases the Staphylococcus aureus from the wound infection was of the same phage type as that isolated pre-operatively from the patient's hair.

It is considered that the human hair is a potential source of cross infection and it is recommended that it be completely covered in the patient and his attendants during minor surgical procedures and the redressing of wounds as well as for surgical operations.

\section{FUNGAL INFECTIONS OF POST-OPERATIVE AURAL CAVITIES}

MARY P. ENGLISH (Bristol General Hospital) Candida albicans and certain species of Aspergillus are the most common causes of fungal infections of post-operative aural cavities in this country. In an examination of dusts from the home of patients with cavities $A$. niger, $A$. fumigatus, $A$. flavus, and $A$. terreus were all found frequently. The isolation by the laboratory of a few colonies of these fungi does not alone, therefore, justify a diagnosis of otomycosis. On the other hand, a genuine case may be missed if scrapings and debris (as distinct from swabs) are not examined. A comparison of clinical with laboratory diagnoses showed that the former are very unreliable.

An outbreak of fungal infections of aural cavities was investigated and shown to be unusual in that 22 of the 48 cases were attributable to $A$. terreus, a very weak pathogen not normally implicated in otomycosis. The outbreak occurred in only two of the hospital's four clinics and staff there had, shortly before, changed over from using a powder of $2 \%$ iodine in boracic acid to nystatin for antifungal therapy. Iodine is fungicidal whereas nystatin is only fungistatic. In addition it was shown that 400 units $/ \mathrm{ml}$. of nystatin was needed to prevent the growth of $A$. terreus, whereas the other species were sensitive to 25 or 50 units. In view of these two facts, it is suggested that the change to nystatin therapy by the clinicians concerned, without laboratory investigation of its effectiveness, was responsible for the outbreak.

\section{CHROMOSOME STUDIES IN ACUTE LEUKAEMIA}

F. J. W. LEWIS, MARGARET MACTAGgART, and M. I. J. ANDREWS (Department of Pathology, Southmead Hospital, Bristol) A chromosomal abnormality specific for chronic myeloid leukaemia is now generally acknowledged, but information on the patterns in acute leukaemia is still limited, possibly because suitable preparations are difficult to obtain and time consuming to analyse. So far no consistent abnormality in acute leukaemia comparable to the $\mathrm{Ph}$ ' chromosome has been recorded, much of the evidence seeming to point only to an increase in aneuploidy. Nevertheless, certain abnormalities specific to individual cases have been found, notably where marrow had been investigated by a 'direct' non-culture technique. The chromosomal patterns 
in 20 cases of acute myeloid leukaemia were investigated, eight of them by a modification of the direct technique. In five of the 20 , cells with 47 chromosomes significant at the $1 \%$ level or greater were found. The value of the direct technique is illustrated by two cases, each with a modal chromosomal number of 47 , the extra chromosome in the one being a medium-sized metacentric and in the other an apparent acrocentric chromosome in the range of the 13-15 group (Denver). Neither of these abnormalities was found in the 72-hour cultures of venous blood. In a third case a possible morphological abnormality involving one of the 13-15 group was found in approximately $20 \%$ of metaphases examined. The significance of these findings and the relationship between the patterns in acute leukaemia and other malignant disorders of the reticulo-endothelial system was discussed.

THE TECHNIQUE OF THE DEMONSTRATION OF FOETAL ERYTHROCYTES AND SOME OF ITS APPLICATIONS

A. B. RAPER (Bristol) Foetal red cells are distinguished from adult cells by their resistance to lysis at $p \mathrm{H}$ 3.4-3.6. This is shown to depend on the solubility of their contained haemoglobin after a limited form of denaturation-drying followed by exposure to cold methanol. Extracellular haemoglobin subjected to the same treatment reacts in exactly the same way. Denaturation that proceeds further abolishes the distinction that must depend upon distinctive properties of the $\beta$ and $\gamma$ chains of the haemoglobin molecule. In particular, the presence of water during alcohol denaturation makes $\mathrm{Hb} \mathrm{A}$ resistant to elution by acid. Thus contamination of the fixative with water artificially produces 'foetal' cells, and the same effect is produced by storage of films for several days in a warm moist atmosphere. No change in the reactivity by adult cells occurs in stored anticoagulated blood, the drying of haemoglobin being an essential first step in the denaturation process concerned. The technique of the test must take account of these facts. In addition to its recognized use in detecting accidental foeto-maternal transfusions, the acid lysis test may be used in determining the life span of foetal cells, and in the investigation of the regulator system that controls the transmission of information from gene to ribosome.

\section{ACID-BASE DISTURBANCES IN HYPERCALCAEMIA}

M. R. WILLS and G. K. McGowaN (Department of
Pathology, The Royal Infirmary, Bristol) It has recently $\stackrel{2}{\stackrel{0}{2}}$ been shown (Wills and McGowan, 1963, 1964) that 으.

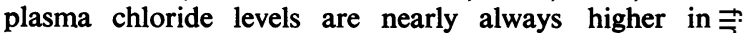
hyperparathyroidism than in hypercalcaemia due to $\stackrel{\oplus}{+}$ other causes, and provide a useful method of differentiating these conditions.

An investigation of possible causes indicates that these are multiple, and include differences in the plasma $\mathbb{D}$ sodium, potassium, phosphate, bicarbonate, and protein concentrations in the two groups of cases.

A direct study of the acid-base state indicates that $a \overrightarrow{0}$ hypochloraemic alkalosis probably plays a significant part in most cases of hypercalcaemia not due to hyper- $\vec{\omega}$ parathyroidism. However, hyperchloraemic acidosis does not seem to play an important part in most cases? of hyperparathyroidism.

\section{REFERENCES}

Wills, M. R., and McGowan, G. K. (1963). J. Bone Jt Surg., 45B, 799. (1964). Brit. med. J. (in the press).

\section{UROKINASE AND EPSILON-AMINO CAPROIC ACID}

A. C. K. LAWRENCE (King's Mill Hospital, Sutton-in- $\overrightarrow{<}$ Ashfield) A controlled trial was carried out in the $\mathscr{6}$ United Kingdom of the use of epsilon-amino caproic $\AA$ acid (E.A.C.A.) in 28 subjects after retropubic pro- $\square$ statectomy. Either $20 \mathrm{~g}$. or $20 \mathrm{mg}$. of E.A.C.A. was administered intravenously in dilute solution over a period of approximately 24 hours commencing immediately after the operation. The two groups were comparable $\frac{\circ}{\circ}$ in all respects examined.

There were fewer examples of larger losses of blood $\overrightarrow{\vec{O}}$ postoperatively and the urine was rendered free of blood 3 sooner after operation in the treated cases. No ill effects $\vec{P}$ were found in this unselected series of elderly men.

The amount and duration of bleeding after operation were not correlated with urokinase activity as measured in vitro by a fibrin plate method, either in the presence $\overline{-}$ or absence of E.A.C.A. The average concentration of insoluble prostatic tissue activator in a cross section of the excised prostate was not correlated with the amount $\frac{0}{3}$ or duration of blood loss after prostatectomy in cases not given E.A.C.A.

It seems likely that the effect of E.A.C.A. is due to its action in haemostatic clots, derived from its effect on the circulating blood. 